\title{
Avaliação bioquímico-nutricional de uma linhagem de soja livre do inibidor de tripsina Kunitz e de lectinas
}

\author{
Biochemical and nutritional evaluation of a soybean line lacking the Kunitz trypsin inhibitor and lectins \\ Maria Fernanda Spegiorin Salla BRUNE ${ }^{1}$, Marcos de Oliveira PINTO², Maria do Carmo Gouveia PELUZIO ${ }^{3}$, \\ Maurílio Alves MOREIRA ${ }^{4}$, Everaldo Gonçalves de BARROS ${ }^{2 *}$
}

\begin{abstract}
Resumo
A soja contém fatores antinutricionais proteicos, inibidores de proteases e lectinas, que limitam o seu uso na alimentação humana e animal. Com a finalidade de reduzir os teores destes antinutricionais na semente de soja, foi desenvolvida uma linhagem sem Inibidor de Tripsina Kunitz (KTI) e Lectina (LEC), pelo Programa de Melhoramento da Qualidade da Soja do BIOAGRO, da Universidade Federal de Viçosa. O presente trabalho teve como objetivo principal a caracterização bioquímico-nutricional dessa linhagem. Foram avaliadas a qualidade nutricional da proteína e as alterações morfológicas no intestino de ratos Wistar alimentados com dietas à base de soja e de caseína. A atividade de inibição de tripsina nos genótipos $\mathrm{KTI}^{+} \mathrm{LEC}^{+}$(Variedade de soja comercial Monarca) foi cerca de 2,8 vezes a do genótipo KTI-LEC- (Isolinha de Monarca livre de KTI e LEC). Os resultados dos valores de PER, NPR e NPU foram melhores na variedade comercial após processamento térmico. A digestibilidade proteica da soja KTILEC foi superior à da variedade comercial. Os valores de digestibilidade para os animais alimentados com dieta à base de farinha de soja KTILEC processada termicamente foram próximos aos observados para animais alimentados com dieta à base de caseína. Verificou-se, também, que os animais alimentados com a soja $\mathrm{KTI}^{+} \mathrm{LEC}^{+}$apresentaram maior nível de alterações na morfologia das microvilosidades intestinais, quando comparados àqueles alimentados com a soja KTI-LEC-. A retirada genética do KTI e LEC teve um impacto positivo na digestibilidade das proteínas da soja, no entanto não melhorou a sua qualidade nutricional.

Palavras-chave: fatores antinutricionais; inibidor de proteases; digestibilidade; microvilosidades intestinais; Glycine max L. Merrill.
\end{abstract}

\begin{abstract}
Soybean seeds contain protein anti-nutritional factors, protease inhibitors, and lectins, which limit their use in human and animal nutrition. Aiming to reduce these factors in soybean seeds, a genotype devoid of Kunitz Trypsin Inhibitor (KTI) and Lectin (LEC) was developed by the Breeding Program for Soybean Quality of the Biotechnology Institute (BIOAGRO) of the Federal University of Viçosa, Minas Gerais, Brazil. The present work aimed at the biochemical and nutritional characterization of this soybean genotype. The protein nutritional quality and intestinal morphological alterations were determined in Wistar rats fed with diets based on soy flour and casein. The trypsin inhibitory activity in normal genotype $\mathrm{KTI}^{+} \mathrm{LEC}^{+}$was approximately 2.8 times greater than that of the KTI-LEC genotype. The PER, NPR, and NPU values obtained after thermal treatment were better for the commercial variety than those of the KTI-LEC genotype. The protein digestibility of the KTI'LEC- soybean was higher than that of the commercial genotype $\mathrm{KTI}^{+} \mathrm{LEC}^{+}$. The digestibility values in animals fed with thermally treated KTI-LEC- soybean flour was close to that observed in animals fed with casein. The animals fed with thermally treated KTI'LEC ${ }^{+}$ soybean flour also presented higher levels of morphological alterations in their intestinal vilosities when compared to those fed with KTI'LEC soybean flour. It can be concluded that the genetic elimination of KTI and LEC positively impacted soybean protein digestibility, however, there was no improvement on its nutritional value.

Keywords: anti-nutritional factors; protease inhibitors; digestibility; intestinal microvilosities; Glycine max L. Merrill.
\end{abstract}

\section{Introdução}

A produção nacional de soja (Glycine max L. Merrill) destina-se, em sua maior parte, à obtenção de óleo e farelo. No Brasil, o consumo do farelo de soja está restrito às indústrias de ração para animais (MONTEIRO et al., 2003). Para esta finalidade, a soja não pode ser utilizada sem tostagem, principalmente quando utilizada na alimentação de animais monogástricos, devido à presença de fatores antinutricionais no grão, os quais interferem na absorção e aproveitamento de nutrientes, limitando o valor nutricional dessa leguminosa.
Entre os fatores antinutricionais encontrados na semente de soja, os principais são os Inibidores de Tripsina Kunitz (KTI) e as Lectinas (LEC) (PUSZTAI et al., 1997; ARMOUR et al., 1998; SILVA, M. R.; SILVA, M. A. A. P., 2000), os quais afetam o crescimento e/ou metabolismo basal de diferentes espécies animais. Segundo Armour et al. (1998), os inibidores de tripsina Kunitz, quando incluídos na dieta, promovem uma diminuição na ingestão de alimento pelos animais, redução na digestão e absorção de proteínas, além de uma menor

Recebido para publicação em 19/5/2008

Aceito para publicação em 8/7/2009 (003518)

${ }^{1}$ Departamento de Ciências Biológicas e da Saúde, Universidade Federal do Mato Grosso - UFMT

2 Departamento de Biologia Geral, Universidade Federal de Viçosa - UFV, Av. Peter Henry Rolfs s/n, Campus Universitário, CEP 36570-000, Viçosa - MG, E-mail: ebarros@ufv.br

3 Departamento de Nutrição e Saúde, Universidade Federal de Viçosa - UFV

${ }^{4}$ Departamento de Bioquímica e Biologia Molecular, Universidade Federal de Viçosa - UFV, Av. PH. Rolfs, s/n, CEP 36570-000, Viçosa- MG, Brasil

${ }^{*}$ A quem a correspondência deve ser enviada 
retenção de nitrogênio absorvido. A lectina, uma glicoproteína de 120 kilodaltons $(\mathrm{kDa})$, possui uma afinidade específica para receptores glicosilados de células epiteliais localizadas nas vilosidades da mucosa intestinal, o que faz com que estas proteínas sejam detrimentais nos processos de digestão, absorção e utilização de nutrientes (NEVEL et al.,1998; SILVA, M. R.; SILVA, M. A. A. P., 2000).

Os efeitos nocivos dos inibidores de proteases em animais alimentados com leguminosa crua são complexos. Muitos estudos com animais monogástricos têm atribuído aos efeitos deletérios, principalmente alterações metabólicas do pâncreas (aumento da secreção enzimática, hipertrofia e hiperplasia) e redução da taxa de crescimento, à presença de inibidores de tripsina na alimentação à base de leguminosas (ALWESALI et al., 1995).

Os fatores antinutricionais presentes em leguminosas são geralmente removidos por tratamento térmico (STANOJEVIC et al. 2004; VEN; MATSER BERG, 2005). No entanto, tal procedimento apresenta um custo elevado, e pode resultar na perda de aminoácidos essenciais e na alteração das propriedades da soja (SIDDHURAJU; MAKKAR; BECKER, 2002). Com a finalidade de reduzir os custos com o processamento térmico, cultivares de soja contendo baixos teores de fatores antinutricionais têm sido desenvolvidos (FRIEDMAN et al., 1991; KRISHNAN, 2001; PALÁCIOS et al., 2004; MORAES et al., 2006).

O Programa de Melhoramento da Qualidade e do Sabor da Soja do BIOAGRO (PMQS) da Universidade Federal de Viçosa - UFV tem desenvolvido um germoplasma especialmente orientado para características especiais de qualidade da soja, visando o seu uso na indústria de alimentos (SEDIYAMA; TEIXEIRA; REIS, 2005). O objetivo do presente estudo foi avaliar parâmetros bioquímicos e nutricionais de uma linhagem de soja com ausência de KTI e lectina em suas sementes, desenvolvida pelo PMQS/UFV.

\section{Material e métodos}

\subsection{Material vegetal}

Os experimentos foram conduzidos utilizando grãos de soja da variedade comercial Monarca e de uma isolinha de Monarca livre de KTI e lectina (KTI-LEC-), desenvolvida pelo PMQS/UFV como descrito a seguir. Progenitores doadores de soja com ausência de KTI (cv. BRM925297) e com ausência de lectina (cv. Columbia) foram cruzados separadamente com a linhagem CAC-1 HyPro, a qual é derivada de cruzamentos entre a variedade CAC-1 e o acesso BARC-8. As linhagens iniciais CAC-1 HyPro sem KTI e CAC-1 HyPro sem lectina foram obtidas por meio de seleção assistida por marcadores moleculares. Essas linhagens foram intercruzadas e as plantas F1 foram autofecundadas, obtendo-se a geração F2. Os perfis eletroforéticos das proteínas presentes nas sementes F2 foram analisados com o objetivo de selecionar genótipos livres de KTI e lectina. Plantas F2 geradas a partir dessas sementes foram cruzadas com a linhagem Monarca HyPro, com o objetivo de recuperar parte das suas características agronômicas desejáveis. Após a obtenção das plantas F1, estas foram autofecundadas. As plantas F2 foram submetidas a dois ciclos de autofecundação, obtendo-se plantas F4. As plantas F2 também foram retrocruzadas (RC) com a linhagem Monarca HyPro, obtendo-se sementes da geração RC1F1, as quais foram autofecundadas, obtendo-se a geração RC1F2. Ao longo de todo o processo de autofecundação, foram realizadas seleções de genótipos homozigotos recessivos para KTI e lectina, e também para elevado teor de proteína (MORAES et al., 2006). Foram utilizados nos experimentos grãos de uma isolinha RC1F2 livre de KTI e lectina e também da variedade Monarca (controle).

\subsection{Obtenção e processamento do farelo de soja}

Os grãos foram lavados, submetidos a tratamento térmico por calor seco $\left(89^{\circ} \mathrm{C}\right.$ por 5 minutos) e quebrados em moinho de martelo para a separação das cascas secas. Os grãos em pedaços foram novamente moídos. O farelo resultante foi peneirado, para garantir a uniformidade das partículas $(0,85 \mathrm{~mm}$ ou 20 mesh), e mantido sob refrigeração a $4{ }^{\circ} \mathrm{C}$ em sacos plásticos até o momento do uso.

Os farelos de soja originados a partir dos grãos da variedade Monarca e da linhagem KTI-LEC- foram processados termicamente, em estufa a $105^{\circ} \mathrm{C}$ durante 40 minutos.

\subsection{Análise bioquímica}

Caracterização do material vegetal quanto à presença de KTI e lectina

O conteúdo do inibidor de tripsina Kunitz foi estimado com base na atividade de tripsina na presença de extratos proteicos de soja, de acordo com o protocolo descrito por Erlanger, Kokowsky e Cohen (1961). A enzima tripsina pancreática bovina (tipo III) e seu substrato N-benzoil-D,L-arginina-pnitroanilida (D,L BApNA) foram diluídos conforme instruções do fabricante (Sigma Chemical Co.). Os resultados foram convertidos em mg de tripsina pura inibida por g de proteína, segundo Kakade et al. (1974).

A presença/ausência de lectina nos grãos de soja foi verificada por eletroforese de proteínas em gel de poliacrilamida, conforme Monteiro (2000).

\section{Caracterização físico-química dos farelos de soja}

Com a finalidade de comparar a composição centesimal da linhagem KTI'LEC, com a variedade Monarca, foi realizada a caracterização físico-química dos farelos de soja. A determinação do conteúdo de proteína foi realizada pelo método semimicro Kjeldhal (ASSOCIATION..., 1984): baseado na determinação do nitrogênio total (nitrogênio inorgânico e orgânico) e utilizandose o fator de correção 6,25, é transformado em proteína bruta. $\mathrm{O}$ conteúdo de lipídios foi determinado conforme procedimento descrito pelo Instituto Adolfo Lutz (1985), em aparelho extrator tipo Soxhlet. Para a determinação do conteúdo de cinzas, foi utilizado o método descrito pela AOAC (ASSOCIATION..., 1984). A concentração de carboidratos foi obtida por diferença em relação aos demais componentes. 


\subsection{Avaliação nutricional}

Os ensaios biológicos foram conduzidos nos laboratórios do Departamento de Nutrição e Saúde (DNS) da Universidade Federal de Viçosa - UFV. A avaliação da qualidade proteica das dietas experimentais foi conduzida por meio de ensaios biológicos, durante 14 dias, utilizando-se 60 ratos machos da raça Wistar (Rattus norvegicus var. Albinus, Rodentia), recémdesmamados, com 23 dias de idade.

As dietas foram preparadas segundo a formulação do American Institute of Nutrition para a dieta AIN-93G (REEVES; NIELSEN; FAHEY, 1993), porém com conteúdo de proteína de 9 a 10\%, exceto para a dieta livre de nitrogênio (aproteica). Após o preparo, o conteúdo de proteína de cada dieta foi determinado pelo método semimicro Kjeldhal, com amostras em triplicata (ASSOCIATION..., 1984). Os tratamentos foram: $\mathrm{LN}=$ dieta livre de nitrogênio (aproteica); CAS = dieta à base de caseína (grupo controle); T1 = dieta à base de farinha de soja KTI'LEC ${ }^{-}$crua; T2 = dieta à base de farinha de soja $\mathrm{KTI}^{+} \mathrm{LEC}^{+}$ crua; $\mathrm{T} 3$ = dieta à base de farinha de soja KTI-LEC- processada termicamente; e T4 = dieta à base de farinha de soja $\mathrm{KTI}^{+} \mathrm{LEC}^{+}$ processada termicamente. $\mathrm{O}$ processamento térmico foi realizado em estufa a $105^{\circ} \mathrm{C}$ durante 40 minutos.

Para a determinação da digestibilidade, as dietas foram marcadas com indigocarmin, na proporção de $200 \mathrm{mg} .100 \mathrm{~g}^{-1}$ de dieta, e foram oferecidas aos animais no $3^{\circ}$ e no $9^{\circ}$ dia de ensaio.

Ao término do ensaio, as fezes e as carcaças dos animais foram secas em estufa com circulação de ar a $105^{\circ} \mathrm{C}$, por 24 horas e, posteriormente, resfriadas, pesadas e trituradas em multiprocessador para determinação do teor de nitrogênio. Os parâmetros nutricionais de digestibilidade verdadeira, coeficiente de eficiência proteica (PER), razão proteica líquida (NPR) e utilização proteica líquida (NPU) foram calculados segundo Sgarbieri (1996).

O delineamento estatístico utilizado foi o inteiramente casualizado com seis tratamentos e dez repetições, considerando cada animal como uma repetição. Os animais foram distribuídos em gaiolas individuais, onde receberam água e alimento ad libitum durante o período experimental. Os experimentos com animais foram conduzidos segundo os Princípios Éticos na Experimentação Animal, preconizados pelo Colégio Brasileiro de Experimentação Animal - COBEA (COLÉGIO..., 2003).

\subsection{Análise histológica}

Após eutanásia, o intestino de cada animal foi coletado para análise histológica. $\mathrm{O}$ intestino foi lavado com tampão fosfato salino gelado para a remoção de partículas fecais, fixado em solução de formalina tamponada a $10 \%$ e incluso em parafina. Após a inclusão, o material foi seccionado em um micrótomo Olympus Cut 4055, obtendo-se cortes de aproximadamente quatro micrômetros de espessura para a montagem das lâminas, as quais foram coradas com hematoxilina/eosina, de acordo com metodologia padrão (LUNA, 1968). As análises histológicas dos cortes foram realizadas em um microscópio de luz da marca Olympus BX50 e analisador de imagem Image - Pro Plus.
Para a análise qualitativa da integridade da mucosa intestinal dos ratos, foram observados dez campos por lâmina, tomados aleatoriamente, com a única restrição de que houvesse, no mínimo, dez microvilosidades no campo escolhido.

\subsection{Análise estatística}

Para as análises estatísticas dos experimentos de determinação da atividade de inibição tríptica e avaliação nutricional, utilizou-se o programa GENES (CRUZ, 1997). Foram realizadas análises de variâncias (ANOVA) para a determinação do valor de "F". Para "F" significativo, utilizouse o teste de Tukey, a 5\% de probabilidade, para comparação entre as médias.

\section{Resultados e discussão}

Os valores de inibição de tripsina dos extratos proteicos da variedade Monarca, crua e tratada termicamente, foram respectivamente 391,83 e 132,63 $\mathrm{mg}$ de tripsina inibida.g ${ }^{-1}$ de proteína, diferindo estatisticamente entre si pelo teste Tukey (Tabela 1). Os valores de inibição de tripsina entre extratos proteicos da variedade Monarca processada e da isolinha $\mathrm{KTI}^{-}$ LEC ${ }^{-}$, crua ou processada termicamente, não diferiram entre si. Estes resultados indicam que o tratamento térmico ao qual os grãos de soja foram submetidos $\left(105^{\circ} \mathrm{C}\right.$ por 40 minutos em calor seco), mostrou-se eficaz na inativação de KTI.

Os resultados demonstram que, considerando a soja in natura, os grãos livres de KTI e lectina apresentaram uma inibição tríptica significativamente menor quando comparada aos grãos da soja convencional. No entanto, é possível observar uma inibição de tripsina, tanto na linhagem $\mathrm{KTI}^{-}$quanto na variedade de soja convencional submetida a tratamento térmico. Essa inibição tríptica residual pode ocorrer devido à presença do inibidor de protease Bowman-Birk (BBI) (MONTEIRO et al., 2003).

A estabilidade térmica dos inibidores de tripisina tem sido bastante discutida em diversos estudos (PALÁCIOS et al., 2004; ROYCHAUDHURI et al., 2003; WIRIYAUMPAIWONG; SOPONRONNARIT; PRACHAYAWARAKOM, 2004). Considerando os principais inibidores de proteases em soja, KTI e BBI (inibidor de quimiotripsina Bowman-Birk), o segundo apresenta maior estabilidade térmica em relação ao primeiro (MARTINEZ; RINCÓN, 1997).

Tabela 1. Inibição da tripsina por extratos proteicos obtidos de grãos de soja da linhagem KTI'LEC' e da variedade Monarca.

\begin{tabular}{|c|c|}
\hline Amostras & mg de tripsina inibida por g de proteína $a^{2,3}$ \\
\hline Monarca crua & $391,83^{\mathrm{a}}$ \\
\hline KTI'LEC ${ }^{-}$crua & $137,32^{\mathrm{b}}$ \\
\hline Monarca processada ${ }^{1}$ & $132,63^{\mathrm{b}}$ \\
\hline KTI'LEC $^{-}$processada ${ }^{1}$ & $134,53^{\mathrm{b}}$ \\
\hline $\begin{array}{l}{ }^{1} \mathrm{O} \text { processamento foi realiza } \\
{ }^{2} \text { conteúdo de proteínas foi } \\
{ }^{3} \text { médias seguidas pelas mesn } \\
\text { de Tukey }(\mathrm{p}<0,05) .\end{array}$ & $\begin{array}{l}\text { em estufa (calor seco) a } 105{ }^{\circ} \mathrm{C} \text { durante } 40 \text { minutos; } \\
\text { minado pelo método BCA (SMITH et al., 1985); e } \\
\text { etras não diferem estatisticamente entre si, pelo teste }\end{array}$ \\
\hline
\end{tabular}


O tratamento térmico aplicado à soja, além de reduzir a atividade de inibição de tripsina, também leva à redução da solubilidade proteica, considerada um importante parâmetro que caracteriza a qualidade nutricional da soja. Portanto, o tratamento térmico não é totalmente adequado como técnica para a redução da atividade dos fatores antinutricionais presentes nos grãos da soja (WIRIYAUMPAIWONG; SOPONRONNARIT; PRACHAYAWARAKOM, 2004).

Para a detecção de lectina em sementes de soja, a metodologia comumente utilizada baseia-se em testes de atividade hemaglutinante (NACHBAR; OPPENHEIM, 1980), pela habilidade dessas glicoproteínas em aglutinar eritrócitos. No entanto, esses testes são semiquantitativos e sujeitos à interferência por outros compostos capazes de aglutinar eritrócitos, como a "soyatoxina", descrita por Vasconcelos et al. (1994).

Novas metodologias para a análise de lectinas em soja têm sido descritas (MAENZ; IRISH; CLASSEN, 1999; RIZZI et al., 2003). Visando confirmar a ausência de lectina nos grãos da linhagem livre de KTI e lectina, foi realizada a técnica de eletroforese (Figura 1).

Com a finalidade de comparar a composição centesimal da isolinha KTI'LEC', com a variedade Monarca, foi realizada a análise físico-química dos grãos de soja dos dois genótipos (Tabela 2). Os resultados obtidos em relação à composição centesimal da soja estão de acordo com os padrões observados na literatura (VIEIRA; CABRAL; PAULA, 1999; MONTEIRO et al., 2003). Considerando a soja cultivada no Brasil, a quantidade de proteína varia de 29,2 a 57,9\% e a de lipídios pode variar de 14,7 a $28,4 \%$, dependendo da variedade cultivada (YAMADA et al., 2003).

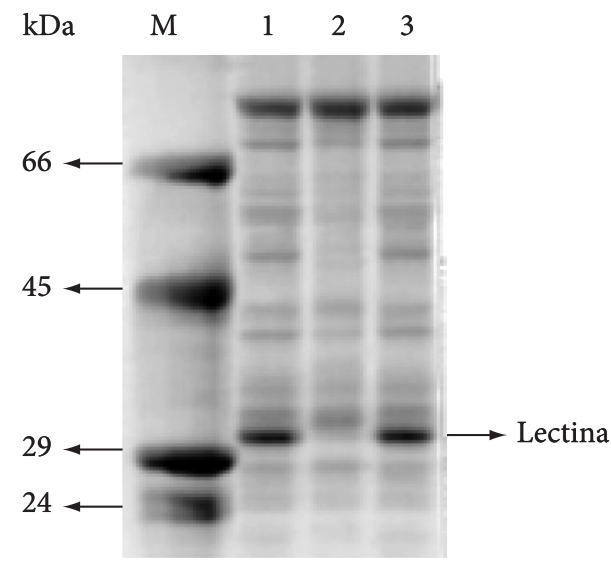

Figura 1. Confirmação da ausência de lectina nos grãos da linhagem KTI-LEC- por SDS-PAGE. M: marcador de peso molecular $(66,45,29$ e $24 \mathrm{kDa}$ ); 1 e 3) Monarca (variedade de soja comercial KTI+LEC+); 2) Linhagem KTI-LEC-.

Tabela 2. Composição química centesimal da variedade de soja Monarca e da linhagem KTI-LEC- (g.100 g g $^{-1}$ em base seca).

\begin{tabular}{ccccc}
\hline Amostras & Lipídios & Cinzas & Proteínas & Carboidratos \\
\hline Monarca & 14,43 & 4,48 & 38,48 & 42,61 \\
KTI-LEC $^{-}$ & 13,18 & 5,77 & 41,96 & 39,09 \\
\hline
\end{tabular}

Os valores de PER, NPR E NPU estão apresentados na Tabela 3. Verifica-se que a dieta do grupo T4 (variedade comercial Monarca processada termicamente) apresentou os maiores valores de PER, NPR e NPU. Pode-se inferir que houve melhora na qualidade proteica desse farelo após o processamento térmico, possivelmente devido à inativação dos fatores antinutricionais.

Os valores da digestibilidade in vivo para as dietas à base de caseína e de farinhas de soja estão expressos na Tabela 4. A digestibilidade indica o quanto das proteínas ingeridas é hidrolisado por enzimas digestivas e absorvidas pelo organismo, constituindo o primeiro fator que afeta a eficiência da utilização proteica da dieta (FRIEDMAN, 1996).

Os valores da digestibilidade verdadeira para as dietas à base de farinhas de soja variaram de 45,10 a 95,60 (Tabela 4). Estes valores estão próximos àqueles encontrados por Vasconcelos et al. (2001) para farinhas de soja convencional e com baixos teores de KTI e lectina, os quais variaram entre 50,90 e 78,30. Observa-se que a digestibilidade da dieta à base de caseína $(99,80)$ não foi estatisticamente diferente da dieta à base de soja KTI-LEC- processada termicamente (95,60 - Grupo T3). Observa-se também que os valores de digestibilidade das dietas contendo farinha de soja KTI-LEC ${ }^{-}$crua $(68,10)$ ou soja convencional tratada termicamente $(73,50)$ não diferiram estatisticamente entre si. Esses resultados mostram que a eliminação genética de KTI e lectina dos grãos de soja promoveu uma melhora significativa na digestibilidade proteica. $\mathrm{O}$ inibidor de tripsina Kunitz, o qual representa cerca de $80 \%$ da atividade

Tabela 3. Valores do Coeficiente de Eficiência Proteica (PER), Razão Proteica Líquida (NPR) e Utilização Proteica Líquida (NPU) das dietas à base de caseína e das farinhas de soja, determinados em experimentos com ratos.

\begin{tabular}{llll}
\hline Dietas & $\mathrm{PER}^{1}$ & $\mathrm{NPR}^{1}$ & $\mathrm{NPU}^{1}$ \\
\hline Caseína & $2,62^{\mathrm{a}}$ & $3,01^{\mathrm{a}}$ & $46,40^{\mathrm{a}}$ \\
$\mathrm{T} 1$ & $0,86^{\mathrm{c}}$ & $1,42^{\mathrm{c}}$ & $22,81^{\mathrm{c}}$ \\
$\mathrm{T} 2$ & $0,33^{\mathrm{d}}$ & $1,07^{\mathrm{d}}$ & $17,90^{\mathrm{c}}$ \\
$\mathrm{T} 3$ & $0,23^{\mathrm{d}}$ & $0,92^{\mathrm{d}}$ & $18,07^{\mathrm{c}}$ \\
$\mathrm{T} 4$ & $1,46^{\mathrm{b}}$ & $1,96^{\mathrm{b}}$ & $38,14^{\mathrm{b}}$ \\
\hline
\end{tabular}

${ }^{1}$ As médias seguidas pelas mesmas letras não diferem estatisticamente entre si, pelo teste de Tukey $(\mathrm{p}<0,05)$; T1 = dieta à base de farinha de soja KTI-LEC crua; T2 = dieta à base de farinha de soja $\mathrm{KTI}^{+} \mathrm{LEC}^{+}$crua; T3 = dieta à base de farinha de soja KTI-LEC processada termicamente; $\mathrm{T} 4$ = dieta à base de farinha de soja $\mathrm{KTI}^{+} \mathrm{LEC}^{+}$processada termicamente.

Tabela 4. Valores de digestibilidade das dietas à base de caseína e das farinhas de soja determinados em experimentos com ratos.

\begin{tabular}{lc}
\hline Dietas & Digestibilidade $^{1}$ \\
\hline Caseína & $99,80^{\mathrm{a}}$ \\
T1 & $68,10^{\mathrm{b}}$ \\
T2 & $45,10^{\mathrm{c}}$ \\
T3 & $95,60^{\mathrm{a}}$ \\
T4 & $73,50^{\mathrm{b}}$ \\
\hline
\end{tabular}

${ }^{1}$ As médias seguidas pelas mesmas letras não diferem estatisticamente entre si, pelo teste de Tukey $(\mathrm{p}<0,05)$; T1 = dieta à base de farinha de soja KTILEC crua; T2 = dieta à base de farinha de soja $\mathrm{KTI}^{+} \mathrm{LEC}^{+}$crua; T3 = dieta à base de farinha de soja KTI-LEC processada termicamente; $\mathrm{T} 4=$ dieta à base de farinha de soja $\mathrm{KTI}^{+} \mathrm{LEC}^{+}$processada termicamente. 

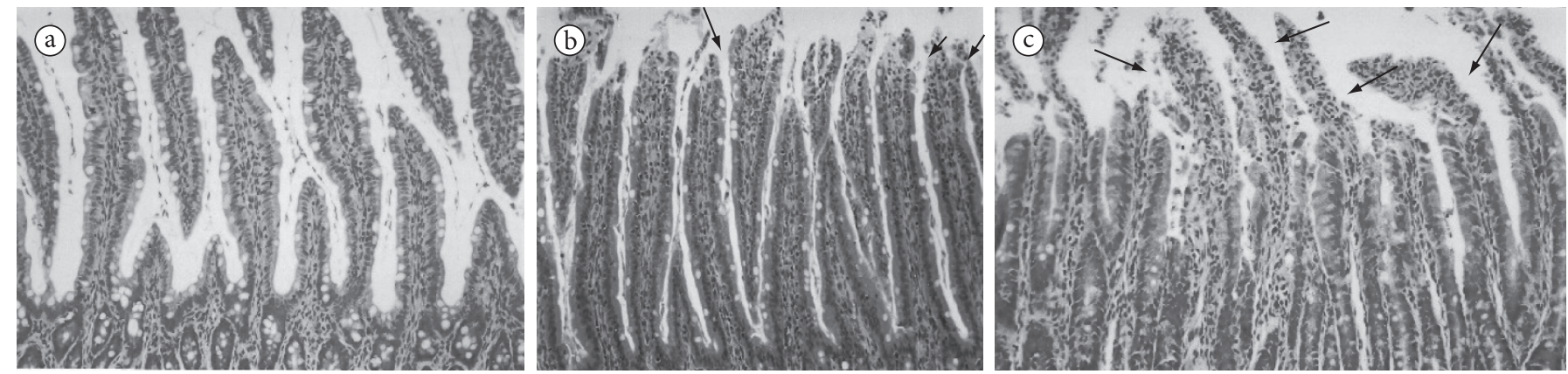

Figura 2. Análise histológica qualitativa de cortes do intestino de ratos alimentados durante 14 dias com dietas à base de soja. a) Intestino delgado de ratos alimentados com dieta à base de soja KTI-LEC; b e c) Intestino delgado de ratos alimentados com dieta à base de soja KTI+LEC+, b) apresentando lesões apicais e c) também lesões que comprometem todo o epitélio da mucosa intestinal. As setas indicam alterações na integridade do epitélio nas microvilosidades intestinais (aumento de 400×).

de inibição tríptica presente nos grãos de soja (TAN-WILSON, 1988), é considerado o mais severo fator antinutricional desta leguminosa, seguido pelas lectinas (VASCONCELOS et al., 2001; RIZZI et al., 2003).

A diferença significativa entre a digestibilidade das dietas à base de soja KTI-LEC'- crua e processada termicamente, pode ser justificada pela presença de fatores antinutricionais termolábeis, distintos de KTI e lectina, os quais possivelmente interferiram no processo de digestão das proteínas da dieta (VASCONCELOS et al., 2001; OLGUIN et al., 2003). Palácios et al. (2004) compararam o desenvolvimento de aves e suínos alimentados com dietas à base de farinha de soja convencional e KTI-LEC-A eliminação genética de KTI e lectina proporcionou uma melhora significativa no desenvolvimento desses animais. No entanto, segundo os autores, apesar da ausência dos principais fatores antinutricionais, a soja KTI'LECsomente deve ser fornecida aos animais após ser submetida a um tratamento térmico.

Apesar do melhor valor de digestibilidade ter sido verificado no farelo de soja livre de KTI e LEC tratados termicamente e que este valor se justificaria pelo fato do processamento térmico melhorar a atuação das proteínas digestivas a partir do momento que eliminou os fatores antinutricionais, o melhor valor de NPU foi encontrado no grupo em que não houve eliminação desses fatores. O índice de utilização proteica líquida varia de acordo com a maior ou menor concentração de proteína na dieta (SGARBIERI, 1996). Então, uma possível justificativa para o maior valor do NPU no grupo T4 seria a presença dos fatores antinutricionais, podendo, nesse caso, ter havido maior disponibilidade de aminoácidos sulfurados para síntese proteica.

Estudos laboratoriais têm relatado a ocorrência de danos na mucosa intestinal de animais alimentados com soja in natura, os quais são atribuídos a compostos tóxicos, como as lectinas (SHARMA et al., 1995). Ao contrário das lectinas, os inibidores de tripsina não interagem com as células da mucosa intestinal (PUSZTAI et al., 1997).

$\mathrm{O}$ aspecto do epitélio intestinal de ratos alimentados com dietas à base de soja contendo KTI e lectina e sem esses fatores pode ser observado na Figura 2. Os animais alimentados com dieta à base de soja $\mathrm{KTI}^{+} \mathrm{LEC}^{+}$crua apresentaram um maior nível de alterações na morfologia das microvilosidades intestinais, quando comparados àqueles alimentados com dieta à base de soja KTI-LEC ${ }^{-}$crua.

Não foram observadas diferenças histomorfológicas qualitativas entre os grupos que receberam as dietas à base de soja processada termicamente, contendo ou não KTI e lectina. Olguin et al. (2003) realizaram uma análise histomorfológica quantitativa do intestino de ratos alimentados com caseína e com farinha de soja processada termicamente (calor úmido a $98{ }^{\circ} \mathrm{C}$ durante 30 minutos). Segundo os autores, os resultados da análise, incluindo medidas do comprimento das vilosidades e profundidade da cripta, não foram diferentes entre os grupos estudados. No entanto, não é possível a comparação entre os resultados, uma vez que a análise realizada neste trabalho foi qualitativa.

Após a análise histológica pela microscopia de luz, observouse que os animais do grupo controle (alimentados com dieta à base de caseína) apresentaram vilosidades bem constituídas, sem lise celular aparente (dados não mostrados). As lesões na mucosa intestinal dos animais alimentados com dieta à base de soja $\mathrm{KTI}^{+} \mathrm{LEC}^{+}$crua variaram entre lesões mais leves, na região apical das microvilosidades (Figura 2b), até níveis mais severos, comprometendo toda a camada de células epiteliais nessa região (Figura 2c).

As alterações da função fisiológica do intestino, causadas por lectinas, são produtos da sua estabilidade aos processos digestivos e também da sua especificidade pelas células da mucosa intestinal (SILVA, M. R.; SILVA, M. A. A. P., 2000).

\section{Conclusões}

A eliminação genética de KTI promoveu uma diminuição significativa nos valores de inibição de tripsina dos extratos proteicos derivados da isolinha KTI'LEC', se comparados aos valores obtidos com a soja convencional.

A temperatura de $105^{\circ} \mathrm{C}$ em calor seco (estufa) durante 40 minutos foi suficiente para promover a inativação dos principais inibidores de tripsina, como o KTI, e da lectina nas sementes de soja convencional.

A eliminação genética do KTI e da lectina promoveu uma melhora acentuada na digestibilidade da proteína de soja, 
sugerindo que estes são os principais fatores antinutricionais presentes nesta leguminosa. Os valores de digestibilidade das farinhas de soja tratadas termicamente e livres de KTI e lectina não diferiram estatisticamente aos da caseína, considerada uma proteína padrão.

Novos experimentos são necessários para o estabelecimento da melhor combinação tempo/temperatura para a inativação dos fatores antinutricionais presentes no grão de soja. Além disso, formas alternativas de processamento térmico devem ser testadas.

\section{Agradecimentos}

Este trabalho foi financiado com recursos provenientes da FAPEMIG e do CNPq.

\section{Referências bibliográficas}

AL-WESALI, M. et al. The influence of pea seed trypsin inhibitors on the in vitro digestibility of casein. Journal of the Science of Food and Agriculture, v. 68, n. 4, p. 431-437, 1995.

ARMOUR, J. C. et al. Protease inhibitors and lectins in soya beans and effects of aqueous heat-treatment. Journal of Science Food and Agriculture, v. 78, n. 2, p. 225-231, 1998.

ASSOCIATION OF OFFICIAL ANALYTICAL CHEMISTS - AOAC. Official methods of analysis of the Association of Official Analytical Chemists. $14^{\text {th }}$ ed. Washington, D.C., 1984.

COLÉGIO BRASILEIRO DE EXPERIMENTAÇÃO ANIMAL COBEA. Princípios éticos na experimentação animal. Disponível em: <http://www.cobea.org.br/index.php>Acesso em: jan. 2003.

CRUZ, C. D. Programa genes aplicativo computacional em genética e estatística. Viçosa, MG: Universidade Federal de Viçosa - UFV, 1997.

ERLANGER, B. F.; KOKOWSKY, N.; COHEN, W. The preparation and properties of two new chromogenic substrates of trypsin. Archives of Biochemistry and Biophysics, n. 95, p. 271-278, 1961.

FRIEDMAN, M. et al. Comparison of a commercial soybean cultivar and an isoline lacking the Kunitz trypsin inhibitor: composition, nutritional value, and effect of heating. Journal of Agricultural and Food Chemistry, v. 39, n. 2, p. 327-335, 1991.

FRIEDMAN, M. Nutritional value of proteins from different food sources. A review. Journal of Agricultural and Food Chemistry, v. 44, n. 1, p. 6-29, 1996.

INSTITUTO ADOLFO LUTZ - IAL. Normas analíticas do Instituto Adolfo Lutz: métodos químicos e físicos para análise de alimentos. 3. ed. São Paulo-SP, 1985.

KAKADE, M. L. et al. Determination of a trypsin inhibitor activity of soy products : a collaborative analysis of an improved procedure. Cereal Chemistry, v. 51, n. 3, p. 376-382, 1974.

KRISHNAN, H. B. Characterization of a soybean [Glycine max (L.) Merr.] mutant with reduced levels of Kunitz trypsin inhibitor. Plant Science, v. 160, n. 5, p. 979-986, 2001.

LUNA, L. G. Manual of histological staining methods of the Armed Forces Institute of Pathology. 3. ed. New York: McGraw-Will, 1968.

MAENZ, D. D.; IRISH, G. G.; CLASSEN, H. L. Carbohydrate-binding and agglutinating lectins in raw and processed soybean meals. Animal Feed Science and Technology, v. 76, n. 3, p. 335-343, 1999.
MARTINEZ, B.; RINCÓN, F. Inhibidores de tripsina. I: Características y significado em la alimentación humana. Alimentaria, v. 279, p. 27-31, 1997.

MONTEIRO, M. R. P. Avaliação da digestibilidade protéica de linhagens de soja com ausência do inibidor de tripsina Kunitz e das isoenzimas lipoxigenases. $69 \mathrm{f}$. Tese (Doutorado em Ciência e Tecnologia de Alimentos)-Universidade Federal de Viçosa, Viçosa, 2000.

MONTEIRO, M. R. P. et al. Avaliação da digestibilidade protéica de genótipos de soja com ausência e presença do inibidor de tripsina Kunitz e lipoxigenases. Brazilian Journal of Food Technology, v. 6, n. 1, p. 99-107, 2003.

MORAES, R. M. M. et al. Assisted selection by specific DNA markers for genetic elimination of the kunitz trypsin inhibitor and lectin in soybean seeds. Euphytica, v. 149, n. 1, p. 221-226, 2006.

NACHBAR, M. S.; OPPENHEIM, J. D. Lectins in the United States diet: a survey of lectins in commonly consumed foods and a review of the literature. American Journal of Clinical Nutrition, v. 33, n. 11, p. 2338-2345, 1980.

NEVEL, V. C. et al. Inhibitory action of spray dried blood plasma and whole egg powder on lectins in extracts of several legume seeds: a quantitative approach. Journal of the Science of Food and Agriculture, v. 77, n. 3, p. 319-326, 1998.

OLGUIN, M. C. et al. Nutritional and antinutritional aspects of an Argentinian soy flour assessed on weanling rats. Journal of Food Composition and Analysis, v. 16, n. 4, p. 441-449, 2003.

PALÁCIOS, M. F. et al. Effect of soybean variety and processing on growth performance of young chicks and pigs. Journal of Animal Science, v. 82, n. 4, p. 1108-1114, 2004.

PUSZTAI, A. et al. Novel dietary strategy for overcoming the antinutritional effects of soya bean whey of high agglutinin content. British Journal of Nutrition, v. 77, n. 6, p. 933-945, 1997.

REEVES, P. G.; NIELSEN, F. H.; FAHEY, G. C. AIN-93 purified diets for laboratory rodents: final report of the American institute of nutrition ad hoc writing committee on the reformulation of the AIN-76A rodent diet. Journal of Nutrition, v. 123, n. 11, p. 1939-1951, 1993.

RIZZI, C. et al. Active soybean lectin in foods: quantitative determination by ELISA using immobilised asialofetuin. Food Research International, v. 36, n. 8, p. 815-821, 2003.

ROYCHAUDHURI, R. et al. Reversible denaturation of the soybean Kunitz trypsin inhibitor. Archives of Biochemistry and Biophysics, v. 412, n. 1, p. 20-26, 2003.

SEDIYAMA, T.; TEIXEIRA, R. C.; REIS, M. S. Melhoramento da soja. In: BORÉM, A. Melhoramento de espécies cultivadas. 2. ed. Viçosa, MG: Universidade Federal de Viçosa - UFV, 2005. cap. 14, p. 553-604.

SGARBIERI, V. C. Proteínas e alimentos protéicos: propriedades, degradações e modificações. São Paulo: Varela, 1996. 517 p.

SHARMA, S. et al. Rat intestinal mucosal responses to a microbial flora and different diets. Gut, v. 36, n. 2, p. 209-214, 1995.

SIDDHURAJU, P.; MAKKAR, H. P. S.; BECKER. K. The effect of ionizing radiation on antinutritional factors and the nutritional value of plant materials with reference to human and animal food. Food Chemistry, v. 78, n. 2, p.187-205, 2002.

SILVA, M. R.; SILVA, M. A. A. P. Fatores antinutricionais: inibidores de proteases e lectinas. Brazilian Journal of Nutrition, v. 13, n. 1, p. 3-9, 2000.

SMITH, P. K. et al. Measurement of protein using bicinchoninic acid. Analytical Biochemistry, v. 150, n. 1, p. 76-85, 1985. 
STANOJEVIC, S. et al. The effect of autoclaving on solublebprotein composition and trypsin inhibitor activity of cracked soybeans. Acta Periodica Technologica (APTEFF), v. 35, p. 49-58, 2004.

TAN-WILSON, A. L. et al. Subclassification of soybean Bowman-Birk isoinhibitors. Journal America Oil Chemistry Society, v. 65, n. 9, p. $1475-1478,1988$.

VASCONCELOS, I. M. et al. Nutritional study of two Brazilian soybean (Glycine max) cultivars differing in the contents of antinutritional and toxic proteins. Journal of Nutritional Biochemistry, v. 12, n. 1, p. 55-62. 2001

VASCONCELOS, I. M. et al. Purification and physicochemical characterization of soyatoxin, a novel toxic protein isolated from soyabeans (Glycine max). Archives of Biochemistry and Biophysics, v. 312, n. 2, p. 357-366, 1994.
VEN, C.; MATSER, A. M.; BERG, R. W. Inactivation of Soybean Trypsin Inhibitors and Lipoxygenase by High-Pressure Processing. Journal of Agricultural and Food Chemistry, v. 53, n. 4, p. 1087-1092, 2005.

VIEIRA, C. R.; CABRAL, L. C.; PAUlA, A. C. O. Composição centesimal e conteúdo de aminoácidos, ácidos graxos e minerais de seis cultivares de soja destinadas à alimentação humana. Pesquisa Agropecuária Brasileira, v. 34, n. 7, p. 1277-1283, 1999.

WIRIYAUMPAIWONG, S.; SOPONRONNARIT, S.; PRACHAYAWARAKOM, S. Comparative study of heating processes for full-fat soybeans. Journal of Food Engineering, v. 65, n. 3, p. 371-382, 2004.

YAMADA, L. T. P. et al. Composição química e conteúdo de ferro solúvel em soja [Glycine max (L.) Merrill]. Ciência Agrotécnica, v. 27, n. 2 , p. $406-413,2003$. 